\title{
Relação entre a integridade da mata ciliar e a distribuição de renda na Bacia Hidrográfica do Rio Una
}

\section{Relationship between the integrity of the riparian forest and the distribution of income in the} River Una Watershed

\author{
J. C. A. Sales ${ }^{1}$; D. C. da Cunha e Silva ${ }^{1,2}$; V. C. Simonetti ${ }^{1 *}$; L. M. Nery ${ }^{3}$; R. W. \\ Lourenço ${ }^{1,2}$ \\ ${ }^{\text {I} P r o g r a m a ~ d e ~ P o ́ s-G r a d u a c ̧ a ̃ o ~ e m ~ C i e ̂ n c i a s ~ A m b i e n t a i s, ~ I n s t i t u t o ~ d e ~ C i e ̂ n c i a ~ e ~ T e c n o l o g i a, ~ U n i v e r s i d a d e ~ E s t a d u a l ~}$ \\ Paulista (Unesp), 18087-180, Sorocaba-SP, Brasil \\ ${ }^{2}$ Departamento de Engenharia Ambiental, Instituto de Ciência e Tecnologia, Universidade Estadual Paulista (Unesp), \\ 18087-180, Sorocaba-SP, Brasil \\ ${ }^{3}$ Centro de Ciências e Tecnologia para a Sustentabilidade, Universidade Federal de São Carlos, 18052-780, Sorocaba- \\ SP, Brasil. \\ *va_simonetti@hotmail.com \\ (Recebido em 01 de abril de 2021; aceito em 10 de julho de 2021)
}

\begin{abstract}
Matas ciliares exercem funções ambientais fundamentais para o equilíbrio ecossistêmico, contudo, essas áreas são frequentemente submetidas à intensas perturbações em virtude de atividades antropogênicas. Dessa forma, o presente estudo avaliou a relação da integridade da mata ciliar da Bacia Hidrográfica do Rio Una em função da distribuição de renda da região, utilizando dados do Índice de Desenvolvimento Humano e o mapeamento da cobertura e uso da terra. Os resultados demonstraram que $23,3 \%$ da área total das áreas de preservação permanente mapeadas é composta por atividades referentes à agropecuária. Também foi verificado que as áreas com os menores valores de integridade de mata ciliar ocorrem em áreas com renda baixa e média. $\mathrm{O}$ estudo traz à luz a necessidade de formulação de políticas públicas que auxiliem na tomada de decisão e que sejam capazes de reverter a desigualdade de renda na região, permitindo um maior desenvolvimento econômico que não esteja vinculado à degradação do meio ambiente.

Palavras-chave: desmatamento, geoprocessamento, indicador socioeconômico.
\end{abstract}

Riparian forests perform essential environmental functions for ecosystem balance; however, these areas are often subjected to intense disturbances due to anthropogenic activities. Thus, the present study sought to evaluate the relationship of the integrity of the riparian forest of the Rio Una Watershed as a function of the region's income distribution, using data from the Human Development Index and mapping the coverage and land use. The results demonstrated that $23.3 \%$ of the total area of the permanent preservation areas mapped is composed of activities related to agriculture. It was also verified that areas with the lowest values of riparian forest integrity occur in areas with low and medium income. The study draws attention to the need to formulate public policies that assist in decision-making and can reverse income inequality in the region, allowing greater economic development that is not linked to environmental degradation.

Keywords: deforestation, geoprocessing, socioeconomic indicator.

\section{INTRODUÇÃO}

Ações de gestão do uso e ocupação da terra em bacias hidrográficas desempenham um papel fundamental na priorização, planejamento e gerenciamento do uso de recursos hídricos, sendo de fundamental importância que pesquisadores, gestores e tomadores de decisão examinem tal questão, com o intuito de se desenvolver políticas e planos que garantam um desenvolvimento sustentável [1-4].

Mata ciliar ou floresta ripária são formações vegetais presentes ao longo das margens de recursos hídricos, que apresentam alta variabilidade espacial e temporal, em virtude de condições bioclimáticas, geomorfológicas e de uso da terra, portanto, são sistemas que se alteram ao longo do tempo por influências de fatores naturais e antrópicos [5-7].

Essas áreas são reconhecidas por sua importância em funções ambientais como o armazenamento de carbono, habitats de diversas espécies, corredores ecológicos, estabilização de margens, regulação de microclima, disponibilização de alimento para a biota e fluxo gênico [7-10]. 
Além disso, a vegetação ripária atua como um verdadeiro "tampão", removendo nutrientes, sedimentos e poluentes provenientes de áreas cultivadas que chegam até os corpos d'água através do escoamento superficial $[5,11,12]$.

As matas ciliares atuam na retenção do escoamento livre da água superficial, diminuindo a sua velocidade, promovendo maior taxa de infiltração e menor suscetibilidade na formação de enxurradas. Esse efeito se deve as raízes das árvores e a presença de serapilheira no solo, protegendo o solo da erosão e do depauperamento do mesmo, uma vez que nutrientes são carreados juntos às enxurradas [5].

Contudo, as áreas ripárias são continuamente submetidas à intensas perturbações em virtude de atividades antropogênicas, sendo frequentemente modificadas [13-16]. Alteração dos fluxos de rios e córregos, poluição, desmatamento, e mudança na cobertura e uso da terra refletem em impactos adversos sobre a conservação da biodiversidade e do funcionamento desses ecossistemas [7, 8]. O principal fator do déficit na biodiversidade de matas ciliares é a perda de habitats em consequência do desmatamento e fragmentação florestal [5].

Historicamente, o progresso das atividades antrópicas está diretamente associado com a substituição da cobertura vegetal por outros usos e ocupações, com a justificativa de que tal ação garante o desenvolvimento econômico [17]. Contudo, essa garantia é ilusória, pois o desmatamento pode resultar em uma melhora econômica momentânea, passando pela concentração de renda, acirramento das desigualdades socioeconômicas e quedas nos índices de desenvolvimento humano [17].

As causas do desmatamento são complexas e não podem ser resumidas em uma única causa [18, 19]. Há de se considerar que, além das causas diretas do desmatamento, é necessária a compreensão de outros fatores, como condições econômicas, demográficas, tecnológicas, culturais e políticas, que operam em múltiplas escalas. Portanto, o desmatamento precisa ser visto como um processo dinâmico, exigindo uma compreensão da dinâmica socioeconômica nas escalas regional e local [20]. Em países em desenvolvimento, por exemplo, a correlação entre os fatores socioeconômicos e sua cobertura florestal, sugere uma questão ambiental relevante a ser entendida para a proposta de adequações de modelos de desenvolvimento vigentes [21].

Rodrigues et al. (2009) [22] procuraram correlacionar os índices de desmatamento na Amazônia brasileira com o Índice de Desenvolvimento Humano (IDH) da região, por entender que o desenvolvimento econômico é frequentemente buscado por meio da conversão da floresta em atividades agropecuárias, mediada pela exploração madeireira, dessa forma, os autores apuraram um padrão de expansão e queda nos níveis de IDH ao longo da fronteira de desmatamento, apontando uma correlação entre o desmatamento, a pobreza e a desigualdade social. Santiago e Couto (2020) [21], sugerem que o desenvolvimento socioeconômico brasileiro é intrínseco ao uso dos recursos florestais, gerando problemas como a melhora passageira do desenvolvimento humano e o favorecimento da concentração de renda, aumentando as desigualdades sociais.

Diante desse contexto, o presente estudo avaliou a relação da integridade da mata ciliar da Bacia Hidrográfica do Rio Una em função da distribuição de renda da região, utilizando o indicador de renda do IDH e o mapeamento da cobertura e uso da terra.

\section{MATERIAL E MÉTODOS}

\section{1 Área de estudo}

A área de estudo corresponde a Bacia Hidrográfica do Rio Una (BHRU), localizada em Ibiúna, na divisa com o município de Piedade (Figura 1), entre a latitude $23^{\circ} 39^{\prime} 23^{\prime}$ ' sul e longitude 47 13 '21' oeste. A BRHU está inserida na Unidade de Gerenciamento de Recursos Hídricos do Sorocaba/Médio Tietê (UGRHI-10).

Ibiúna situa-se na região sudeste do estado de São Paulo, a $70 \mathrm{~km}$ da capital, com uma população de aproximadamente 71.217 habitantes [23]. O clima da BHRU é definido como Cwb, subtropical com inverno seco e verão ameno, de acordo com a classificação de Köppen, enquanto a vegetação original é do tipo ombrófila densa montana [24]. 


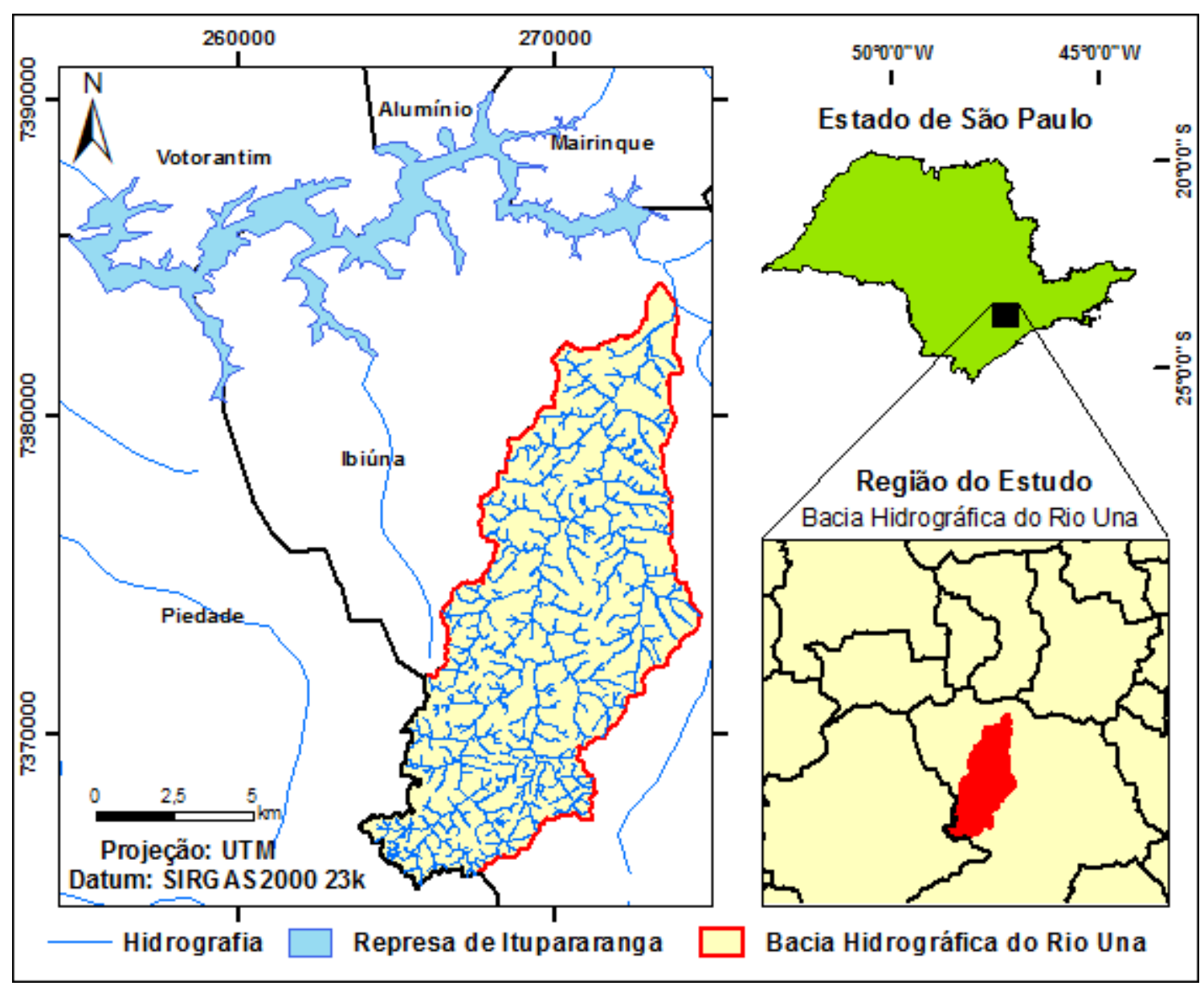

Figura 1. Mapa de localização da Bacia Hidrográfica do Rio Una. Fonte: Autoria própria.

A bacia hidrográfica em estudo é de grande relevância devido à sua contribuição para os municípios da região. A nascente do rio Una se encontra nos limites dos municípios de Piedade e Ibiúna, entre os Bairros do Saltinho e Bairro do Salto, seguindo em direção ao Bairro da Vargem, passando pela Rodovia Júlio Dal Fabbro em direção à zona urbana do município de Ibiúna, e pela Rodovia Bunjiro Nakao até desaguar no rio Sorocabuçu, próximo a estrada vicinal IbiúnaMairinque. A união do rio Una, com os rios Sorocabuçu e o Sorocamirim, originam o rio Sorocaba, sendo esse último, um dos principais afluentes do rio Tietê [25].

\subsection{Desenvolvimento humano}

A variável referente ao desenvolvimento socioeconômico da área em estudo foi obtida através da síntese do Índice de Desenvolvimento Humano (IDH) da BHRU. O IDH é obtido através de três dimensões sociais: longevidade; educação e renda, de modo que para o cálculo desse índice, tais dimensões foram avaliadas de forma independente, antes de se obter o indicador propriamente dito. O IDH por setor censitário do município de Ibiúna foi elaborado através de uma adaptação do IDH Global, realizada em 2012, pelo Instituto de Pesquisa Econômica Aplicada (IPEA), Programa das Nações Unidas para o Desenvolvimento do Brasil (PNUD), e pela Fundação João Pinheiro [26].

\subsection{Dimensão renda (DRenda)}

A dimensão renda, ou subíndice renda, procura mensurar a capacidade média de aquisição de bens e serviços de uma população, sendo composta e expressa pela renda per capita [27]. Nesse estudo, utilizamos dessa mesma definição ao analisarmos esse subíndice para os setores censitários, de modo que, a renda setorizada per capita trata-se da razão do rendimento nominal total pela 
população total residente nos domicílios de cada setor [23]. Valores de máximo e mínimo de referência foram atribuídos de acordo com o chamado dólar-paridade-poder-de-compra (\$PPC), usado no IDH-Global [26].

O \$PPC pode ser compreendido como um indicador de comparação entre as moedas das nações, sendo usado como fator de conversão de uma determinada moeda para o dólar americano [28]. Portanto, convertendo os valores máximo e mínimo expressos em \$PPC para o real brasileiro, a renda per capita mensal do Brasil possui valores máximo e mínimo de $\mathrm{R} \$ 4.033,00$ e $\mathrm{R} \$ 8,00$, respectivamente. $\mathrm{O}$ valor de referência máxima se refere ao menor valor de renda per capita entre os dez residentes mais ricos do país, e o valor mínimo corresponde ao mínimo adotado pelo IDH Global [29].

Assim o cálculo da $D_{\text {Renda }}$ da bacia hidrográfica por setores censitários, adaptado do IDH Global, foi calculada de acordo com a Equação 1.

Sendo:

$$
D_{\text {Renda }}=\frac{\left(\log _{r p s}-\log _{r \min }\right)}{\left(\log _{r \max }-\log _{r \min }\right)}
$$

$D_{\text {Renda }}$ é a Dimensão de renda da BHRU;

$\log _{\text {rps }}$ é o Logaritmo da renda per capita do setor censitário;

$\operatorname{Logr}_{\min }$ é o Logaritmo da referência mínima;

Logr $_{\max }$ é o Logaritmo da referência máxima.

As variáveis utilizadas no cálculo da $\mathrm{D}_{\text {Renda }}$ foram obtidas através das informações contidas no censo 2010 (DomicilioRenda_SP2) [23]. Os dados coletados referem-se ao total do rendimento nominal mensal dos domicílios particulares permanentes, e contemplam às construções com finalidade específica para a habitação, e o total do rendimento nominal mensal dos domicílios particulares improvisados, que se referem às ocupações que não são destinadas exclusivamente para a habitação, como barracões, carroças, prédios em construção, lojas, entre outras unidades não-residenciais, além do número total de residentes por setores censitários [23].

\subsection{Uso da terra e cobertura vegetal}

O mapa do uso da terra e cobertura vegetal da BHRU foi obtido por meio de geotecnologias, como sensoriamento remoto e geoprocessamento. Para tanto, foi utilizada a imagem orbital proveniente do satélite óptico Landsat 8 , adquirida no site do Instituto Nacional de Pesquisas Espaciais (INPE). As bandas utilizadas nesse estudo foram 2, 3 e 4, todas com resolução espacial de 30 metros. Essas bandas foram reamostradas para a resolução de 15 metros através da banda pancromática do mesmo satélite. Posteriormente, o sistema de coordenadas foi reprojetado para o Sistema de Projeção Universal Transverse Mercator (UTM), Datum Horizontal WGS 1984, e as correções geométricas foram realizadas na imagem adquirida para o Hemisfério Sul. O mapeamento foi sintetizado com o auxílio de uma composição RGB verdadeira, utilizando técnicas de interpretação visual e pós classificação, considerando os seguintes critérios: tamanho e forma; cor e tonalidade; localização do objeto na paisagem; textura e estrutura da paisagem. A imagem obtida, data de novembro de 2018.

As categorias de uso da terra e cobertura vegetal mapeadas foram adaptadas do Manual Técnico de Uso da Terra [30], sendo classificadas em: Área Urbana (AU), que correspondem aos usos que não possuem natureza agrícola, como sedes municipais, vilas, sistemas viários e áreas urbanas isoladas; Agricultura (AG): áreas com lavoura; Reflorestamento (RE): áreas com atividades de silvicultura; Floresta (FL): formação arbórea em diferentes estágios sucessionais de desenvolvimento; Campo (CA): áreas campestres com estrato vegetal predominantemente herbáceo-arbustivo; Pastagem (PA): atividades voltadas para a produção pecuária; e Área Alagada (AA): corpos d'água continentais naturais ou artificiais.

Entende-se como áreas naturais as áreas de Floresta, Campo e Áreas Alagadas. As categorias: Área Urbana; Reflorestamento; Pastagem e Agricultura, foram consideradas nesse estudo como atividades de uso antrópico. Por fim, após obtido o mapa de uso da terra e cobertura vegetal para o 
ano de 2018, o mesmo foi corroborado através de visitas em campo, a partir da definição de pontos aleatórios para a verificação e confirmação dos tipos de uso da terra e cobertura vegetal. Ao todo, 100 pontos foram visitados e avaliados com auxílio de um GPS portátil Garmin eTrex 30x e câmera digital. Quando verificado algum uso da terra e cobertura vegetal mapeado diferentemente do que foi observado in loco, as devidas correções foram feitas através da edição dos vetores e a retificação do mapeamento.

\section{5 Índice de integridade da mata ciliar (IIMC)}

Para avaliarmos a integridade e a conservação das matas ciliares da BHRU, calculamos o Indicador de Integridade de Matas Ciliares (IIMC), proposto e adaptado por Silva et al. (2017) [31]. Sendo assim, primeiramente delimitamos as áreas de preservação permanente (APP's), com auxílio do software ArcGis 10.3. A delimitação das APP's foi realizada de acordo com a Lei Federal 12.651 de 25 de maio de 2012, através da geração de vetores buffer no entorno dos cursos d'água, lagos e nascentes da BHRU [32]. Posteriormente, os vetores buffer foram utilizados para o recorte do plano de informação referente ao uso da terra e cobertura vegetal do ano de 2018, a fim de se verificar as categorias de uso da terra e cobertura vegetal presentes nas APP's, uma vez que a conservação das APP's está condicionada à cobertura vegetal existente [33]. Desse modo, podemos entender que o IIMC atribui valores às áreas de APP's verificadas, de acordo com a porcentagem de sua respectiva cobertura vegetal.

Na metodologia proposta e adaptada por Silva et al. (2017) [31], valores de 0 a 1 são atribuídos para a avaliação das APP's, de modo que, quão menor é a pontuação atribuída menor é a integridade da mata ciliar. A porcentagem que define a integridade das APP's é descrita na Tabela 1. Como resultado do IIMC, foi obtido o mapa de IIMC, referente a integridade da mata ciliar das sub-bacias da BHRU.

Tabela 1. Relação entre a porcentagem da integridade da mata ciliar com a pontuação atribuída na avaliação das áreas de preservação permanente.

\begin{tabular}{cc}
\hline Integridade da Mata Ciliar em \% & Pontuação \\
\hline IIMC $\leq 60$ & 0 \\
$60<$ IIMC $\leq 70$ & 0,2 \\
$70<$ IIMC $\leq 80$ & 0,4 \\
$80<$ IIMC $\leq 90$ & 0,6 \\
$90<$ IIMC $\leq 95$ & 0,8 \\
IIMC $\geq 95$ & 1 \\
\hline
\end{tabular}

Fonte: Silva et al. (2017) [31].

\subsection{Obtenção das Sub-Bacias do Rio Una}

Bacias hidrográficas podem ser desmembradas em unidades menores, denominadas sub-bacias, dependendo do exutório considerado ao longo do seu eixo central. Dessa forma, sub-bacias podem ser compreendidas como áreas de drenagem dos cursos d'água tributários de um rio principal [34]. Dentro desse contexto, adotamos o termo "sub-bacias" para diferenciar os níveis, ou as escalas, de abrangência da bacia hidrográfica em estudo. A apresentação dos dados censitários referente a dimensão renda (DRenda), bem como o índice de integridade de mata ciliar (IIMC), foram apresentados em uma análise contemplando as sub-bacias da BHRU. Para a delimitação das subbacias utilizamos a ferramenta Watershed do software ArcGis 10.3 [35]. Essa ferramenta realiza tal delimitação de forma automática, através da declividade do terreno, fluxo do curso d'água e ponto do exutório. 


\section{RESULTADOS E DISCUSSÃO}

Nesse estudo foi considerado o IDH a nível municipal, compreendendo a sua relevância como indicador de qualidade de vida [36]. Avaliando os dados obtidos do Atlas do Desenvolvimento Humano do Brasil [26], baseado nas informações do último censo demográfico de 2010 [23], o Brasil, o estado de São Paulo, assim como o município de Ibiúna apresentaram melhorias no que se refere ao IDH. Cabe ressaltar que, o município de Ibiúna obteve uma considerável melhoria no IDH desde o ano 1991, quando esse índice era classificado como muito baixo. Já no ano de 2000, o IDH do município foi classificado como baixo, e em 2010 passou a ser considerado alto. A Tabela 2 mostra a comparação do IDH com seus subíndices, a nível nacional, estadual, municipal e da BHRU no ano de 2010.

Tabela 2. Comparação entre o índice do desenvolvimento humano (IDH) com os seus subíndices: renda, longevidade e educação, para os diferentes níveis territoriais.

\begin{tabular}{ccccc}
\hline \multicolumn{5}{c}{ Ano 2010 } \\
\hline Local & $\begin{array}{c}\text { IDH } \\
\text { Renda }\end{array}$ & $\begin{array}{c}\text { IDH } \\
\text { Longevidade }\end{array}$ & $\begin{array}{c}\text { IDH } \\
\text { Educação }\end{array}$ & IDH \\
Brasil & 0,739 & 0,816 & 0,637 & 0,727 \\
São Paulo & 0,789 & 0,845 & 0,719 & 0,783 \\
(Estado) & & 0,832 & 0,614 & 0,71 \\
Ibiúna (SP) & 0,70 & 0,81 & 0,81 & 0,76 \\
BHRU & 0,665 & & & \\
\hline
\end{tabular}

\subsection{Dimensão renda (DRenda)}

Os resultados obtidos para a DRenda por setores censitários da BHRU são apresentados na Figura 2. O subíndice renda encontrado, 0,665, é classificado como médio, de acordo com valores estabelecidos pelo PNUD (2013) [26]. A renda média per capita da bacia hidrográfica em 2010 foi de $\mathrm{R} \$ 540,44$, com uma variação de renda per capita, máxima e mínima, de $\mathrm{R} \$ 1.060,30$ e $\mathrm{R} \$$ 270,38 respectivamente.

É possível inferir que a concentração de renda na BHRU ocorre no centro urbano de Ibiúna, correspondendo a porção norte da bacia hidrográfica em estudo. Já as regiões que tiveram a DRenda classificada como média e baixa, foram observados, respectivamente, na região central e sul da BHRU, apresentando valores de renda per capita inferiores quando comparadas com a região norte.

As concentrações de renda podem ser compreendidas como reflexo dos níveis de densidade populacional e localização geográfica, que favoreçam, ou não, o desenvolvimento de atividades econômicas [33]. Áreas com características físicas que impeçam o estabelecimento de ocupações antrópicas, como áreas de acentuado declive ou que possuem predominância de cobertura florestal em áreas legalmente protegidas, possuirão menor densidade populacional, e consequentemente, menor valor de renda per capita, principalmente quando comparadas com áreas urbanas. 


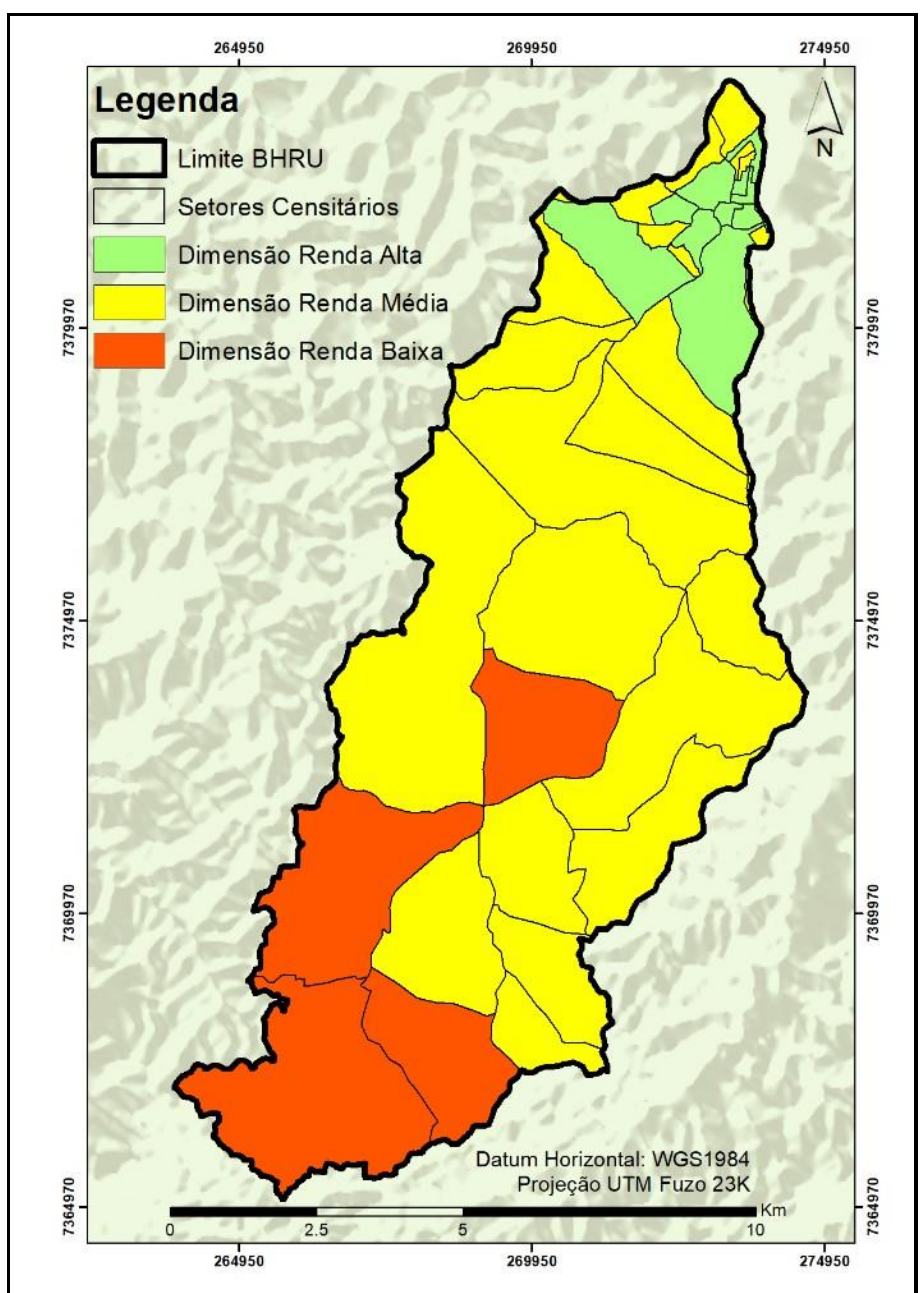

Figura 2. Mapa temático demonstrando a distribuição da dimensão (subíndice) renda do índice de desenvolvimento humano na Bacia Hidrográfica do Rio Una. Fonte: Autoria própria.

Cabe ressaltar algumas limitações quanto à aplicação dessa metodologia, assim como observado em outro estudo [36]. Primeiramente, a única variável utilizada para indicar o rendimento mensal é aquela que se refere aos responsáveis pelos domicílios particulares permanentes e improvisados, não correspondendo a renda total do setor censitário. E a segunda limitação se refere aos dados disponibilizados pelo IBGE, os quais consideram apenas a renda dos chefes de família desses domicílios, excluindo os residentes de outros tipos de domicílios. Contudo, o número de pessoas residentes em outros tipos de domicílios, que não são classificados como particulares ou improvisados, é pequeno, não impactando significativamente no resultado do trabalho.

\subsection{Uso da terra e cobertura vegetal}

Através do mapeamento do uso da terra e cobertura vegetal foi possível verificar as diferentes categorias de uso e ocupação da BHRU (Tabela 3), assim como as respectivas porcentagens de ocupação. É possível verificar que a categoria de uso da terra e cobertura vegetal com maior área de ocupação é a categoria Floresta, com 37,06\%, seguido da categoria Agricultura, com 35,98\% da área total da bacia. Entretanto, somando todos os tipos de uso da terra referente às atividades antrópicas (AU; RE; PA; AG), a área total ocupada é de 54,13\%, representando 5.221,47 ha da área em estudo. O restante do uso da terra e cobertura vegetal da BHRU é composto por áreas naturais (FL; CA; AA), com uma área total ocupada de 4.423,86 ha, ou seja, igual a 45,87\% da área de estudo. 
Tabela 3. Distribuição das classes de uso da terra e cobertura vegetal na Bacia Hidrográfica do Rio Una no ano de 2018.

\begin{tabular}{ccc}
\hline Classes & Área (ha) & \% \\
\hline Áreas urbanas (AU) & 1461,76 & 15,16 \\
Reflorestamento (RE) & 235,71 & 2,44 \\
Pastagem (PA) & 54,01 & 0,56 \\
Agricultura (AG) & 3469,99 & 35,98 \\
Campo (CA) & 761,12 & 7,89 \\
Áreas alagadas (AA) & 88,08 & 0,91 \\
Floresta (FL) & 3574,66 & 37,06 \\
Total & 9645,33 & 100,00 \\
\hline
\end{tabular}

A partir da Figura 3 é possível verificar uma expansão urbana expressiva na região centro-sul da BHRU, principalmente ao longo do percurso do rio Una, em contraposição a predominância de áreas agrícolas na região central e sudoeste da bacia hidrográfica. As áreas de vegetação, como florestas e campos, estão distribuídas heterogeneamente ao longo da BHRU, sendo observado que quanto maior a concentração das áreas urbanas menor é a presença de áreas de vegetação. A região de maior concentração urbana está a nordeste da bacia hidrográfica, próximo à porção baixa da BHRU.

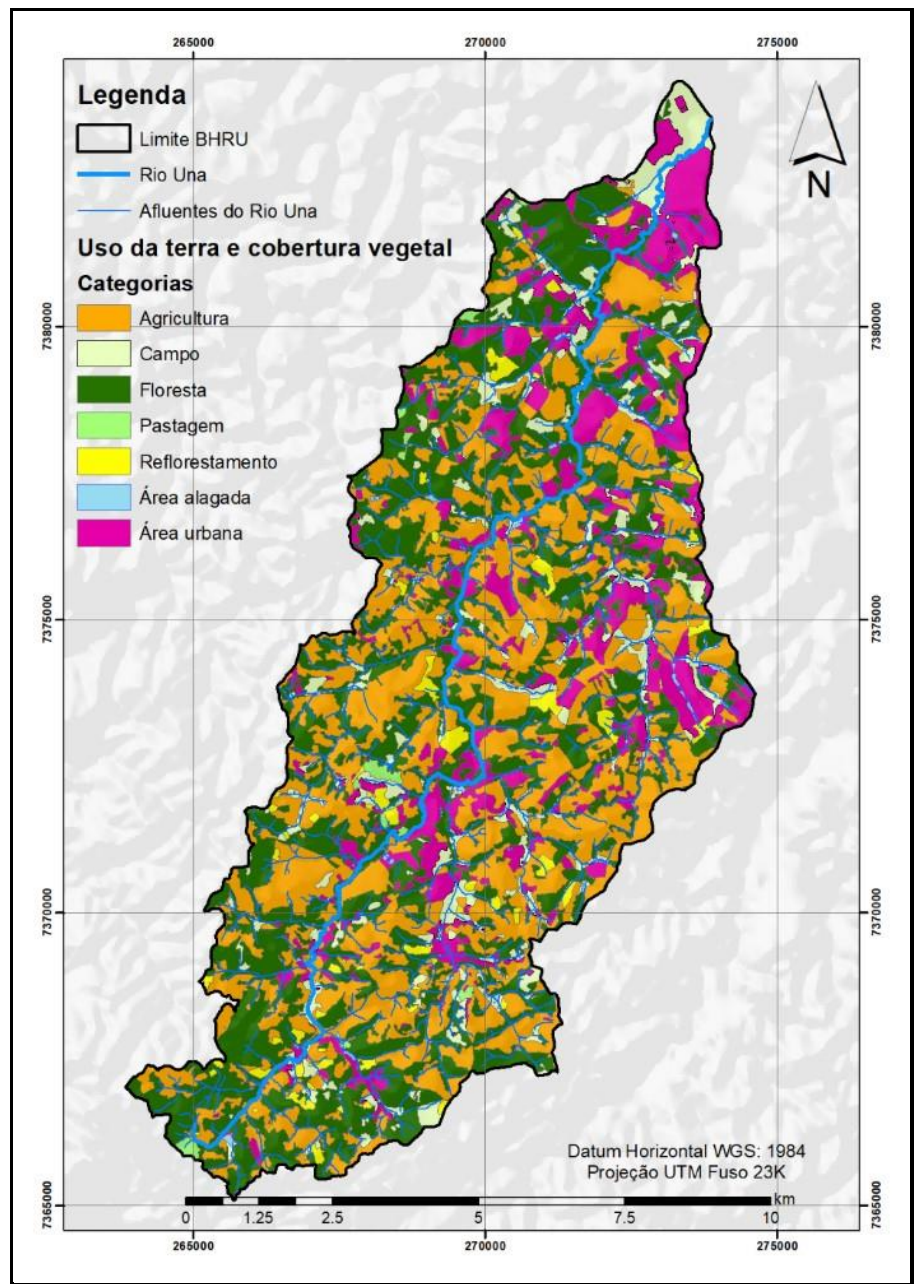

Figura 3. Mapa do uso da terra e cobertura vegetal da Bacia Hidrográfica do Rio Una no ano de 2018. Fonte: Autoria própria. 
Os estudos realizados por Silva et al. (2017) [31] também revelaram áreas de cultivos agrícolas de curto e longo período distribuídos por toda a BHRU, assim como ressaltam que a classe de florestas apresenta a maior porcentagem em área dentre as verificadas na bacia hidrográfica, ou seja, obtiveram resultados semelhantes ao presente estudo.

Outro estudo realizado na BHRU, constatou a presença predominante da agricultura na porção central da bacia hidrográfica, acrescido de um alto potencial para a ocupação urbana [37]. A predominância da agricultura na região central pode ser vista como reflexo das características físicas e de relevo na região, já que locais que possuem declividade acentuada são compreendidos como locais inaptos para o desenvolvimento de atividades agrárias, em virtude da impossibilidade de utilização de maquinário agrícola e alta suscetibilidade à erosão [38, 39]. Lopes et al. (2018) [40], verificaram que o declive da BHRU ocorre, predominantemente, entre as classes de declividade de $8 \%$ a $45 \%$, com áreas pontuais ao norte e ao sul da bacia hidrográfica, com declividade acima de $45 \%$. Dentro desse contexto, áreas que favoreçam o estabelecimento das atividades agrícolas podem ser entendidas como áreas suscetíveis na remoção e substituição da vegetação natural por outros usos e ocupações.

\subsection{Integridade da mata ciliar}

A manutenção da qualidade da água é fundamental para a sobrevivência de diferentes espécies, além da garantia da qualidade de vida da população [12, 41]. Contudo, a crescente expansão da população e das atividades agrícolas, pressionam os recursos hídricos devido às altas demandas. Essa pressão pode ser avaliada de acordo com os índices de conservação da vegetação ripária, geração de resíduos sólidos domiciliares e a presença de sistemas de tratamento e abastecimento de água [31]. Portanto, estudos que contemplem a integridade da mata ciliar são de grande valia.

Os resultados acerca do mapeamento do uso da terra e cobertura vegetal nas áreas de APP's, demonstram que $64,1 \%$ da área total é composta por áreas naturais, como floresta, com 999,72 ha, campos e áreas alagadas, computando uma área de 335,78 ha. 23,26\% da área total das APP's é composta por atividades referentes à agricultura e pastagem, com uma área de 484,69 ha (Tabela $4)$.

Tabela 4. Distribuição das classes de uso da terra e cobertura vegetal nas áreas de preservação permanente ao longo da Bacia Hidrográfica do Rio Una.

\begin{tabular}{ccc}
\hline Classes & Área (ha) & \% \\
\hline Área urbana & 232,99 & 11,18 \\
Reflorestamento & 30,38 & 1,46 \\
Floresta & 999,72 & 47,98 \\
Campo & 247,70 & 11,89 \\
Agricultura & 475,87 & 22,84 \\
Pastagem & 8,82 & 0,42 \\
Áreas alagadas & 88,08 & 4,23 \\
\hline Total & $\mathbf{2 0 8 3 , 5 7}$ & $\mathbf{1 0 0}$ \\
\hline
\end{tabular}

O estudo realizado por Simonetti et al. (2019) [12], na APA Itupararanga que contempla a BHRU, identificou riscos associados aos processos de antropização das áreas de APP's do rio Una. Os autores verificaram que a cobertura vegetal das matas ciliares era de $73,80 \%$, e relataram processos erosivos nas margens e descarte de lixo.

Diversos estudos realizados no que diz respeito ao uso da terra em áreas de APP's obtiveram resultados semelhantes ao encontrado na BHRU. Kauano e Passos (2008) [42] obtiveram cerca de $40 \%$ da área total da bacia hidrográfica do rio da Gama, na cidade de Tijucas do Sul, Paraná, em áreas naturais. Araújo e Mendes (2014) [43], verificaram mais de 50\% de áreas naturais em APP's, na Serra da Aratanha, Ceará, e consideram esse resultado como um bom indicador do estado de conservação dessas APP's. Entretanto, considerando a Lei Federal 12.651/2012, APP's devem ser 
$100 \%$ protegidas, promovendo a conservação dos recursos hídricos das bacias hidrográficas [12, 32].

A Figura 4 apresenta a diversidade dos usos da terra e cobertura vegetal nas APP's, sendo possível verificar espacialmente a distribuição desses usos na bacia hidrográfica, com destaque para as áreas de agricultura, que se apresentam pulverizadas ao longo de toda a BHRU, assim como as áreas urbanizadas nas APP's. Portanto, torna-se evidente a ocupação irregular nessas áreas, sendo que os impactos negativos dessas ocupações já foram constatados em diversos estudos que avaliaram a qualidade da água do reservatório de Itupararanga [12, 41, 44], que identificaram uma deterioração na qualidade da água associado ao excesso de nutrientes aportados, como nitrogênio e fósforo, que potencializou o índice de estado trófico do reservatório.

Além disso, considerando as importantes funções ambientais garantidas pela preservação da mata ciliar, a degradação dos recursos hídricos em função da degradação das áreas ripárias, também contribui com o aumento substancial nos gastos com tratamento de água para abastecimento público, de modo que esse gasto pode ser de cinquenta a cem vezes maior [45, 46].

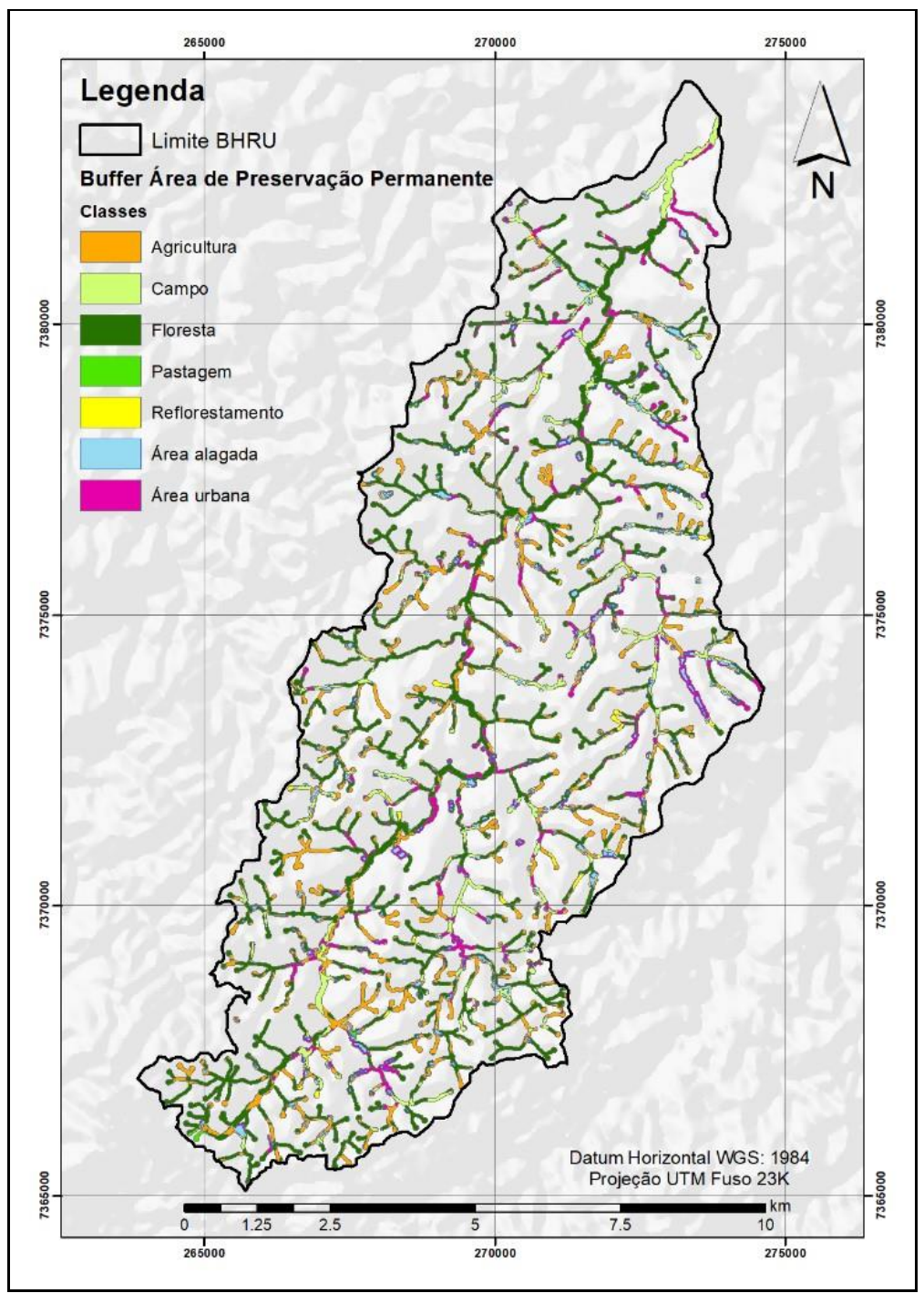

Figura 4. Mapa das áreas de preservação permanente na Bacia Hidrográfica do Rio Una. Fonte: Autoria própria.

Com base nos resultados obtidos referente as áreas de uso da terra e cobertura vegetal das APP's, foi possível verificar a porcentagem da integridade da mata ciliar na BHRU e calcular o IIMC para cada sub-bacia, conforme verificado na Figura 5. É possível observar que as porções sul, oeste e 
noroeste da BHRU apresentam os valores mais baixos de IIMC, presente nas sub-bacias 2, 4, $6 \mathrm{e}$ 11 , com valores menores que 0,2 , o que significa que essas sub-bacias possuem APP's com áreas de vegetação ripária inferior a $70 \%$. As sub-bacias com melhores condições de conservação das APP's são as de número 3, 7 e 10, com integridade da cobertura vegetal entre $70 \%$ e $80 \%$.

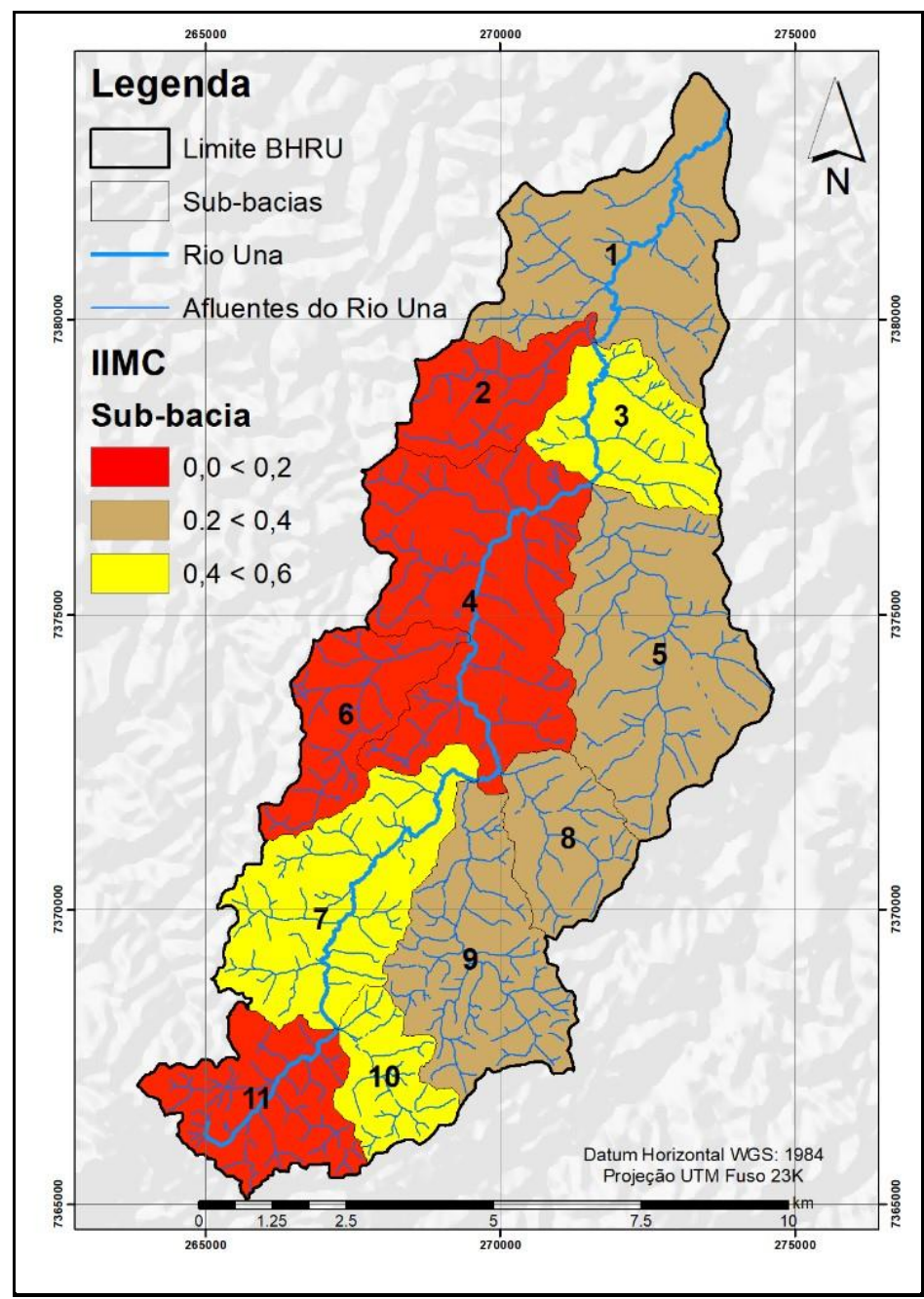

Figura 5. Mapa do índice de integridade da mata ciliar (IIMC) por sub-bacia. Fonte: Autoria própria.

Os baixos valores de IIMC encontrados nesse estudo podem sem compreendidos como reflexo da expansão urbana e agrícola da BHRU, e como resultado do processo de anistia de crimes ambientais e de desmatamento, uma vez que supressões da cobertura vegetal em APP's anteriores a publicação da Lei 12.651/2012 foram absolvidas [24, 31].

Foram verificados que os valores de IIMC entre 0 e 0,40 ocorrem nas sub-bacias em que, majoritariamente, apresentaram DRenda baixa e média. Cabe ressaltar que a BHRU possui o menor valor de IDH renda quando comparada com o estado de São Paulo, o município de Ibiúna e o Brasil. Há um consenso em se compreender que uma economia em crescimento possui efeitos positivos em indicadores ambientais, como melhorias nos sistemas de saneamento ambiental. Contudo, há também consenso em se relacionar efeitos adversos no meio ambiente com a pobreza, pois se compreende que locais mais pobres exercem maior pressão sobre os recursos naturais, enquanto os mais ricos, por possuírem maior acúmulo de capital humano e social, atingem uma melhor consciência ambiental [14].

Dessa forma, mecanismos relacionados ao Pagamento por Serviços Ambientais (PSA) podem ser vistos como estratégias que aliam a conservação de ecossistemas e a melhoria das condições de subsistência [47], a implementação de um programa de PSA contribui com o desenvolvimento e 
estabelecimento de uma política pública voltada para conservação dos recursos naturais [48]. Como exemplo de um programa de PSA que poderia ser implementado na BHRU, podemos citar o Programa Produtor de Água, o qual remunera, proporcionalmente, os favorecidos do programa de acordo com os benefícios ambientais alcançados pela recuperação da vegetação e conservação do solo [47]. Entre esses benefícios destacam-se: redução da erosão e sedimentação; redução dos custos de tratamento de água; melhorias quali-quantitativas nos recursos hídricos; e melhorias no habitat para a ictiofauna [47].

Arraes et al. (2012) [19] ao avaliarem a influência do IDH municipal sobre os níveis de desmatamento na Amazônia Legal, verificaram que o indicador possui um efeito positivo e estatisticamente significante para redução da degradação ambiental, ou seja, melhores condições de desenvolvimento humano tendem a aumentar a probabilidade para a ocorrência de menores taxas de desmatamento.

Além disso, observa-se que os valores mais baixos de IIMC ocorrem em áreas onde predominam a atividade agrícola. Faria e Almeida (2016) [49], ao investigarem como o comércio internacional afeta o desmatamento na Amazônia, identificaram que, à medida que a abertura ao comércio aumenta o desmatamento também aumenta, de modo que as atividades agropecuárias impulsionam o desmatamento na região. De acordo Armenteras et al. (2017) [20], na maioria dos países da América Latina, o acesso aos mercados e às atividades agrícolas e florestais são as principais causas do desmatamento.

Dessa forma, a identificação de áreas críticas quanto às áreas mais afetadas pela ausência de matas ciliares, não apenas direcionará a atenção de planejadores e gestores para a zona mais problemática, mas também reduzirá o custo econômico envolvido na abordagem de medidas de conservação do solo e da água [4]. Considerando que o desenvolvimento humano, que envolve expectativa de vida, educação e renda, tem efeito positivo no crescimento e na conservação da floresta [50], é necessário o desenvolvimento de políticas públicas que favoreçam o aumento do nível educacional e a redução da desigualdade, visando delimitar a expansão desordenada das atividades antrópicas.

\section{CONCLUSÃO}

Os resultados obtidos demonstram que as áreas com menores valores de renda estão associadas com os menores valores de integridade da mata ciliar. Também, foi constatado que os menores valores de integridade ocorrem em áreas predominantemente agrícolas, sendo importante ressaltar a necessidade da formulação de políticas públicas que auxiliem na tomada de decisão que favoreçam a adequação dos meios de produção para modelos mais sustentáveis, que ao mesmo tempo sejam capazes de reverter a desigualdade de renda na região, que atuem na recuperação das áreas degradadas e na conservação dos recursos naturais, permitindo um maior desenvolvimento econômico que não esteja vinculado à degradação do meio ambiente.

O presente estudo contribui com o subsídio de informações que podem auxiliar na formulação de políticas públicas e no gerenciamento da implementação das mesmas, contribuindo na fiscalização do cumprimento das leis ambientais no sentido de analisar que as áreas de preservação permanente não estão sendo protegidas em sua totalidade, e trazendo à luz a importância de uma expansão econômica sustentável mais efetiva.

\section{REFERÊNCIAS BIBLIOGRÁFICAS}

1. Silva DCC, Albuquerque Filho JL, Oliveira RA, Lourenço RW. Aplicação do NDWI para avaliar a disponibilidade de água em bacias hidrográficas. Rev Univ Vale do Rio Verde. 2017 Jul;15(1):774-783, doi: 10.5892/ruvrd.v15i1.2842

2. Puno G, Puno R C. Watershed conservation prioritization using geomorphometric and land use-land cover parameters. Global J Environm Sci Managem. 2019;5(3):279-294, doi: 10.22034/GJESM.2019.03.02

3. Simonetti VC, Silva DCC, Rosa AH. Análise da influência das atividades antrópicas sobre a qualidade da água da APA Itupararanga (SP), Brasil. Geosul. 2019 Jul;34(72):1-27, doi: 10.5007/19825153.2019v34n72p01 
4. Uniyal B, Jha MK, Verma, AKK, Anebagilu PK. Identification of critical areas and evaluation of best management practices using SWAT for sustainable watershed management. Sci Total Environm. 2020 Nov;744:140737, doi: 10.1016/j.scitotenv.2020.140737

5. Vogel HF, Zawadzki CH, Metri R. Florestas ripárias: importância e principais ameaças. SaBios: Rev Saúde Biol. 2009 Jan-Jun;4(1):24-30.

6. Silva DCC, Moro MK, Moya KJ, Pinheiro MM, Simonetti VC. Proposta metodológica para definição de áreas prioritárias para recuperação vegetal de áreas de preservação permanente. Rev Gestão Sustent Amb. 2018 Dez;7(4):540-562, doi: 10.19177/rgsa.v7e42018540-562

7. Riis T, Kelly-Quinn M, Aguiar FC, Manolaki P, Bruno D, Bejarano MD, Clerici N, Fernandes MR, Franco JC, Pettit N, Portela AP, Tammeorg O, Tammeorg P, Rodríguez-González PM, Dufour S. Global Overview of Ecosystem Services Provided by Riparian Vegetation. BioScience. 2020 May;70(6):501514, doi: 10.1093/biosci/biaa041

8. Richardson DM, Holmes PM, Esler KJ, Galatowitsch SM, Stromberg JC, Kirkman SP, Pyšek P, Hobbs RJ. Riparian vegetation: degradation, alien plant invasions, and restoration prospects. Diversity Distributions. 2007 Jan;13(1):126-139, doi: 10.1111/j.1366-9516.2006.00314.X

9. Oliveira RA, Silva DCC, Simonetti VC, Stroka EAB, Sabonaro DZ. Proposição de Corredor Ecológico entre duas Unidades de Conservação na Região Metropolitana de Sorocaba. Rev Depto Geogr. 2016;32:61-71, doi: 10.11606/rdg.v32i0.116467

10. Alvarenga LA, Mello CR, Colombo A, Cuartas LA. Hydrologic impacts due to the changes in riparian buffer in a headwater watershed. CERNE. 2017 Apr;23(1):95-102, doi: 10.1590/01047760201723012205

11. Oliveira CA, Kliemann HJ, Correchel V, Santos FCV. Avaliação da retenção de sedimentos pela vegetação ripária pela caracterização morfológica e físico-química do solo. Rev Bras Eng Agríc Ambient. 2010 Dez;14(12):1281-1287, doi: 10.1590/S1415-43662010001200005

12. Simonetti VC, Silva DCC, Rosa AH. Proposta metodológica para identificação de riscos associados ao relevo e antropização em áreas marginais aos recursos hídricos. Sci Plena. 2019 Fev;15(2):025301, doi: 10.14808/sci.plena.2019.025301

13. Celentano D, Rousseau GX, Engel VL, Zelarayán M, Oliveira EC, Araujo ACM, Moura EG. Degradation of riparian forest affects soil properties and ecosystem services provision in eastern Amazon of Brazil. Land Degradation \& Development. 2017 Feb;28(2):482-493, doi: 10.1002/ldr.2547

14. Macfarlane WW, Gilbert JT, Jensen ML, Gilbert JD, Hough-Snee N, McHugh PA, Wheaton JM, Bennett SN. Riparian vegetation as an indicator of riparian condition: Detecting departures from historic condition across the North American West. J Environm Manag. 2017 Nov;202(2):447-460, doi: 10.1016/j.jenvman.2016.10.054

15. Alemu T, Bahrndorff S, Hundera K, Alemayehu E, Ambelu A. Effect of riparian land use on environmental conditions and riparian vegetation in the east African highland streams. Limnologica. 2017 Sep;66:1-11, doi: 10.1016/j.limno.2017.07.001

16. Chua EM, Wilson SP, Vink S, Flin N. The influence of riparian vegetation on water quality in a mixed land use river basin. River Research and Applications. 2019 Mar;35(3):259-267, doi: 10.1002/rra.3410

17. Santiago AR, Couto HTZ. Socioeconomic development versus deforestation: considerations on the sustainability of economic and social growth in most Brazilian municipalities. Environm Develop. 2020 Sep;35:100520-100531, doi: 10.1016/j.envdev.2020.100520

18. Geist HJ, Lambin EF. What drives tropical deforestation? A meta-analysis of proximate and underlying causes of deforestation based on subnational case study evidence. LUCC Report Series; 4. Louvain-laNeuve (BE): LUCC International Project Office; 2001.

19. Arraes ERA, Mariano FZ, Simonassi AG. Causas do desmatamento no Brasil e seu ordenamento no contexto mundial. Rev Econ Sociol Rural. 2012 Mar;50(1):119-140, doi: 10.1590/S010320032012000100007

20. Armenteras D, Espelta JM, Rodríguez N, Retana J. Deforestation dynamics and drivers in different forest types in Latin America: Three decades of studies (1980-2010). Global Environm Change. 2017 Sep;46:139-147, doi: 10.1016/j.gloenvcha.2017.09.002

21. Santiago AR, Couto HTZ. Socioeconomic development versus deforestation: considerations on the sustainability of economic and social growth in most Brazilian municipalities. Environm Develop. 2020 Sep;35:100520, doi: 10.1016/j.envdev.2020.100520

22. Rodrigues ASL, Ewers RM, Parry L, Souza Júnior C, Veríssimo A, Balmford A. Boom-and-bust development patterns across the amazon deforestation frontier. Science. 2009 Jun;324(5933):1435- 1437, doi: $10.1126 /$ science. 1174002

23. IBGE: Instituto Brasileiro de Geografia e Estatística. Base de Informações do Censo Demográfico 2010 : Resultados do Universo por setor censitário. Rio de Janeiro: IBGE; 2012. 
24. Sales, JCA, Silva DCC, Lourenço RW. Análise espacial da avifauna e sua correlação com indicadores ambientais na bacia hidrográfica do Rio Una (SP). Bol Geogr. 2019;37:202-217, doi: 10.4025/bolgeogr.v37i2.37839

25. Cavani ACM, Albuquerque-Filho JL. Plano de Bacias, Mapa Diagnóstico. São Paulo: Comitê de Bacias Hidrográficas do Rio Sorocaba e Médio Tiete - CBH-SMT e Instituto de Pesquisas Tecnológicas da Universidade de São Paulo; 2008.

26. PNUD: Programa das Nações Unidas para o Desenvolvimento. Atlas do Desenvolvimento Humano no Brasil 2013 [Internet]. Brasília (DF): PNUD; 2013 [citado em 20 jan 2017]. Disponível em: https://atlasbrasil.org.br/

27. Brasil RG, Macedo JJ. Novas dimensões para o IDH segundo a abordagem das capacitações. Economia \& Região. 2016 Jan-Jun;4(1):103-120, doi: 10.5433/2317-627X.2016v4n1p103

28. Prearo LC, Maraccini MC, Romeiro MC. Fatores determinantes do Índice de Desenvolvimento Humano dos Municípios do Estado de São Paulo. Rev Bras Pol Púb. 2015;5(1):132-155, doi: 10.5102/rbpp.v5i1.2960

29. Atlas BR: Atlas do Desenvolvimento Humano no Brasil. Índice de desenvolvimento humano municipal - IDHM: metodologia [Internet]; 2021 [citado em 13 jun 2021]. Disponível em: https://atlasbrasil.org.br/acervo/atlas

30. IBGE: Instituto Brasileiro de Geografia e Estatística. Manuais técnicos em Geociências: Manual técnico do uso da terra. 3. ed. Rio de Janeiro: IBGE; 2013.

31. Silva DCC, Albuquerque-Filho JL, Oliveira RA, Lourenço RW. Metodologia para análise do potencial de degradação dos recursos hídricos em bacias hidrográficas. Caderno de Geografia. 2017;27:50, doi:10.5752/p.2318-2962.2017v27n50p455

32. Brasil. Lei $\mathrm{n}^{\circ} 12.651$, de 25 de maio de 2012. Dispõe sobre a proteção da vegetação nativa; altera as Leis $\mathrm{n}^{\text {os }} 6.938$, de 31 de agosto de 1981, 9.393, de 19 de dezembro de 1996, e 11.428, de 22 de dezembro de 2006; revoga as Leis $\mathrm{n}^{\text {os }} 4.771$, de 15 de setembro de 1965, e 7.754, de 14 de abril de 1989, e a Medida Provisória ${ }^{\circ}$ 2.166-67, de 24 de agosto de 2001; e dá outras providências. Diário Oficial da União. 28 mai 2012;(Seção 1):1.

33. Skorupa LA. Área de Preservação Permanente e Desenvolvimento Sustentável. Jaguariúna (SP): Embrapa Meio Ambiente; 2003.

34. Santana DP. Manejo integrado de Bacias Hidrográficas. Sete Lagoas (MG): Embrapa Milho e Sorgo; 2003.

35.ESRI: Environmental Systems Research Institute. ArcGIS Desktop. Release 10.1. Redlands Environmental Systems Research Institute; 2014.

36. Abreu MVS, Oliveira JC, Andrade VDA, Meira AD. Proposta metodológica para o cálculo e análise espacial do IDH intraurbano de Viçosa - MG. Rev Bras Est Pop. 2011 Jan-Jun;28(1):169-186, doi: 10.1590/S0102-30982011000100009

37. Silva DCC, Albuquerque-Filho JL, Sales, JCA., Lourenço, RW. Uso de indicadores morfométricos como ferramentas para avaliação de Bacias Hidrográficas. Rev Bras Geogr Fís. 2016;9:627-642, doi: 10.26848/rbgf.v9.2.p627-642

38. Lepsch IF. Formação e conservação dos solos. 2. ed. São Paulo (SP): Oficina de Textos; 2010.

39. Garcia YM, Campos S, Tagliarini FSN, Campos M, Rodrigues BT. Declividade e potencial para mecanização agrícola da bacia hidrográfica do ribeirão pederneiras - Pederneiras/SP. Braz J Biosyst Engineering. 2020;14(1):67-72, doi: 10.18011/bioeng2020v14n1p62-72

40. Lopes ERN, Souza JC, Albuquerque Filho JL, Lourenço RW. Modelagem ambiental de bacias hidrográficas: caracterização morfométrica e pedológica da bacia do rio Una -Ibiúna, Brasil. Geosul. 2018 Jan-Abr;33(66):105-127, doi: 10.5007/2177-5230.2018v33n66p105

41. Melo DS, Gontijo ESJ, Frascareli D, Simonetti VC, Machado LS, Barth JAC, Moschini-Carlos V, Pompêo ML, Rosa AH, Friese K. Self-organizing maps for evaluation of biogeochemical processes and temporal variations in water quality of subtropical reservoirs. Water Resources Res. 2019 Nov;55(12):10268-10281. doi: 10.1029/2019WR025991

42. Kauano ÉE, Passos E. Análise do uso da terra em áreas de preservação permanente da bacia hidrográfica do rio da Gama, Tijucas do Sul, Paraná. Rev Acad Ciênc Agrár Ambient. 2008 Jun;6(2):181-190, doi: 10.7213/cienciaanimal.v6i2.10466

43. Araújo TS, Mendes LMSM. Análise espaço-temporal do estado de conservação da Serra da Aratanha/Ceará. GeoUECE. 2014 Jan-Jun;3(4):330-341.

44. Frascareli D, Beghelli FGDS, Silva SCD, Moschini-Carlos V. Heterogeneidade espacial e temporal de variáveis limnológicas no reservatório de Itupararanga associadas com o uso do solo na Bacia do Alto Sorocaba-SP. Rev Ambiente \& Água. 2015 Dec;10(4):770-781. doi: 10.4136/ambi-agua.1715

45. Tundisi JG, Tundisi TM. Impactos potenciais das alterações do Código Florestal nos recursos hídricos. Biota Netrop. 2010 Dez;10(4):67-75, doi: 10.1590/S1676-06032010000400010 
46. Tundisi JG, Matsumura-Tundisi T, Ciminelli VS, Barbosa FA. Water availability, water quality water governance: the future ahead. IAHS Press. 2015;366:75-79, doi: 10.5194/piahs-366-75-2015

47. Manfredini FN, Guandique MEG, Morais LC. Custos de oportunidade de um programa de pagamento por serviços ambientais. Rev Iberoamericana Econ Ecol. 2019;29(1):84-103.

48. Corrêa JCP, Tonello KC, Franco FS. Hydrological and environmental analysis of the Pirajibu-Mirim watershed, Sorocaba, SP, Brazil. Rev Ambiente \& Água. 2016 Dez;11(4):943-953, doi: 10.4136/1980993X

49. Faria WR, Almeida AN. Relationship between openness to trade and deforestation: Empirical evidence from the Brazilian Amazon. Ecological Economics. 2016 Jan;121:85-97, doi: 10.1016/j.ecolecon.2015.11.014

50. Assongu SA, Jingwa BA. The role of human development on deforestation in Africa: amodelling-based approach. Int J Green Econ. 2012 Jan;6(4):317-330, doi: 10.1504/IJGE.2012.051493 